\title{
A bacteriophage detection tool for viability assessment of Salmonella cells
}

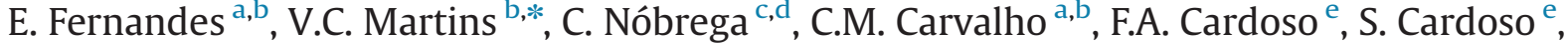 \\ J. Dias $^{\mathrm{b}}$, D. Deng ${ }^{\mathrm{b}}$, L.D. Kluskens ${ }^{\mathrm{a}}$, P.P. Freitas ${ }^{\mathrm{b}, \mathrm{e}}, \mathrm{J}$. Azeredo ${ }^{\mathrm{a}}$ \\ a IBB-Institute for Biotechnology and Bioengineering, Centre of Biological Engineering, University of Minho Campus de Gualtar, 4700-057 Braga, Portugal \\ ${ }^{\mathrm{b}}$ International Iberian Nanotechnology Laboratory, Av. Mestre José Veiga, 4715-330 Braga, Portugal \\ ${ }^{\mathrm{c}}$ Life and Health Sciences Research Institute (ICVS), School of Health Sciences, University of Minho, Campus de Gualtar, $4700-057$ Braga, Portugal \\ ' ICVS/3B's, PT Government Associated Laboratory, Braga/Guimarães, Portugal \\ e INESC-MN-Instituto de Engenharia de Sistemas e Computadores-Microsistemas e Nanotecnologias and IN-Institute of Nanoscience and Nanotechnology, \\ PT Government Associated Laboratory, Rua Alves Redol 9, 1000-029 Lisbon, Portugal
}

\section{A R T I C L E I N F O}

Article history:

Received 19 July 2013

Received in revised form

26 August 2013

Accepted 28 August 2013

Available online 7 September 2013

Keywords:

Bacteriophage

Salmonella

Cell viability

Viable but non-culturable bacteria

Magnetoresistive biochip

Magnetic nanoparticles

\begin{abstract}
A B S T R A C T
Salmonellosis, one of the most common food and water-borne diseases, has a major global health and economic impact. Salmonella cells present high infection rates, persistence over inauspicious conditions and the potential to preserve virulence in dormant states when cells are viable but non-culturable (VBNC). These facts are challenging for current detection methods. Culture methods lack the capacity to detect VBNC cells, while biomolecular methods (e.g. DNA- or protein-based) hardly distinguish between dead innocuous cells and their viable lethal counterparts. This work presents and validates a novel bacteriophage (phage)-based microbial detection tool to detect and assess Salmonella viability. Salmonella Enteritidis cells in a VBNC physiological state were evaluated by cell culture, flow-cytometry and epifluorescence microscopy, and further assayed with a biosensor platform. Free PVP-SE1 phages in solution showed the ability to recognize VBNC cells, with no lysis induction, in contrast to the minor recognition of heat-killed cells. This ability was confirmed for immobilized phages on gold surfaces, where the phage detection signal follows the same trend of the concentration of viable plus VBNC cells in the sample. The phage probe was then tested in a magnetoresistive biosensor platform allowing the quantitative detection and discrimination of viable and VBNC cells from dead cells, with high sensitivity. Signals arising from 3 to 4 cells per sensor were recorded. In comparison to a polyclonal antibody that does not distinguish viable from dead cells, the phage selectivity in cell recognition minimizes falsenegative and false-positive results often associated with most detection methods.
\end{abstract}

(c) 2013 Elsevier B.V. All rights reserved.

\section{Introduction}

The ingestion of food, its derivatives and water contaminated with microbial pathogens (e.g. Escherichia coli, Campylobacter sp. or Salmonella sp.) is responsible for about 2.2 million deaths annually. To reduce the incidence and economic burden of foodborne diseases, the World Health Organization (WHO) has been enforcing the establishment of a surveillance program to

\footnotetext{
* Corresponding author. Tel.: + 351 253140112; fax: + 351253140119.

E-mail addresses: elisabete.fernandes@deb.uminho.pt (E. Fernandes), veronica.romao@inl.int, veronicamartins@ist.utl.pt (V.C. Martins), claudianobrega@ecsaude.uminho.pt (C. Nóbrega), carlacarvalho@deb.uminho.pt (C.M. Carvalho),fcardoso@inesc-mn.pt (F.A. Cardoso), scardoso@inesc-mn.pt (S. Cardoso), joaodias5@gmail.com (J. Dias), dengd@mit.edu (D. Deng), kluskens@deb.uminho.pt (L.D. Kluskens), paulo.freitas@inl.int (P.P. Freitas), jazeredo@deb.uminho.pt (J. Azeredo).
}

assure the safety of alimentary products along the food chain"from farm to fork" (WHO, 2005). Such actions have stimulated R\&D activities seeking for new methods for microbial detection, in particular bioanalytical technologies (Nugen and Baeumner, 2008; Velusamy et al., 2010). In contrast to the actual culture-based methods, biosensors have started to offer great advantages due to their faster and more sensitive response (Boehm et al., 2007; Ivnitski et al., 1999). However, they still suffer from a notorious drawback: the false-negative results (i.e. the failure to detect a virulent pathogen when present). The occurrence of falsenegatives is often attributed to technological limitations, such as low sensitivity, matrix interferences and/or inhibitions. Also, many bacteria are reported to enter in a "dormant" state where they can be hardly distinguished from live and dead cells. Nevertheless, they keep their virulence and the ability to resuscitate when in favorable conditions (Oliver, 2005, 2010). In such a state, bacteria will not grow in standard solid culture media, and as a result will 
not be detected as colony forming units (CFU), the gold-standard detection method. "Dormant" bacteria have therefore been called viable but non-culturable (VBNC) cells. The VBNC physiological state is reported for several pathogenic bacteria and occurs under the influence of different cellular stress conditions, in particular in the presence of disinfectant agents (Khamisse et al., 2012). This represents a major problem in food facilities because VBNC bacteria may persist and contaminate food, regardless of the disinfection treatments (Firmesse et al., 2012).

Most of the methods used for VBNC detection involve the use of fluorescent probes in the characterization of the cell physiological activity (Breeuwer and Abee, 2000; Joux and Lebaron, 2000).

Among various approaches, the direct viable count (DVC) method combined with nucleic acid staining (Baudart et al., 2002; Besnard et al., 2000), the measurement of respiratory activity (Winding et al., 1994) or other metabolic activities (Duncan et al., 1994; Nybroe, 1995), and the estimation of bacterial membrane potential (Deere et al., 1995) or membrane integrity by fluorophores penetration (Caron, 1998) can be quoted. Although most physiological probes allow evaluation at the single-cell level, they are time-consuming and do not provide information on the identity of the assayed cells.

Detection methods based on DNA analysis (e.g. PCR-Polymerase Chain Reaction) (Keer and Birch, 2003; Lu et al., 2009) or flow cytometry (Nebe-von-Caron et al., 2000; Phe et al., 2005; Suller and Lloyd, 1999) have recently been developed to identify the cell's physiological state. In PCR methods, either the reverse transcriptase (RT)-PCR, which detects mRNA, a biomolecule that has a half-life of about 3-5 min after cell death (Keer and Birch, 2003), or new DNA-intercalating dyes such as ethidium monoazide and propidium monoazide that block the amplification of DNA from dead cells (Lu et al., 2009) are often used. A possible drawback in these PCR-based methods is the effect that the length of the PCR amplicon may have on the efficiency of removal of the dead cell signal (Banihashemi et al., 2012).

The same principle of actuation is the basis to other viability indicator dyes, mostly fluorescent molecules widely used in epifluorescence microscopy and flow cytometry. Cell membrane diffusion probes and DNA-intercalating dyes are used for tagging cells with damaged (dead cells) or undamaged (viable cells) membranes. For instance the commercially available kit LIVE/ DEAD $^{\circledR}$ BacLight $^{\mathrm{TM}}$ from Molecular Probes, also used in this work, offers a combination of two dyes: a green fluorochrome (SYTO9) able to enter all cells (used to assess total cell counts) and a red fluorochrome (propidium iodide-PI) that selectively enters compromised cells. These methods can fairly easily distinguish between viable and dead cells (Banihashemi et al., 2012; Weaver, 1997). However, since they rely on the membrane integrity as a discrimination factor, intermediate states are generally misclassified or simply identified as an "unknown" and poorly characterized population. For this reason, in flow cytometry, the way to circumvent this limitation is through a well-defined gating strategy that is highly dependent on how accurate the positive and negative controls are for the defined cell populations (e.g. viable, compromised and dead).

In this work, a bacteriophage is used to discriminate between VBNC cells and dead cells. Phages are viruses that infect only bacteria, while being innocuous to humans. They have been recently considered very interesting biorecognition elements and biodetection tools due to their high specificity to bacteria, robustness, great stability (even under adverse environmental conditions) and extended shelf-life (Edgar et al., 2006; Santos et al., 2010). These characteristics, combined with their innocuous nature and low production costs, led the Food and Drug Administration (FDA) to approve some phage-based diagnostic protocols for pathogen detection (e.g. Mycobacterium tuberculosis, Yersinia pestis,
Bacillus anthracis, and Staphylococcus aureus; Schofield et al., 2012). Significant progress has been reported in the phage-based detection of foodborne and waterborne pathogens (Hagens and Loessner, 2007; Singh et al., 2012; Smartt et al., 2012). Studies on the utilization of phages for the detection of VBNC bacteria are still limited and have been applied only to E. coli 0157:H7 (Awais et al., 2006; Oda et al., 2004). Those studies either lack the capability to directly discriminate VBNC from dead cells (Awais et al., 2006) or do not even mention the ability to detect the VBNC physiological state (Tlili et al., 2013).

In this work, a broad spectrum virulent phage (PVP-SE1) from the Myoviridae family was used as a biorecognition element to distinguish viable and VBNC cells from dead Salmonella Enteritidis cells. After determining the best bactericidal and bacteriostatic compound to induce the VBNC state to Salmonella cells, various tests on the phage ability to discriminate the different Salmonella cell physiological states (viable, VBNC and heat killed cells) were made. A phage-based magnetoresistive biochip was developed where phages are immobilized at surface probe sites, and magnetic nanoparticles functionalized with anti-Salmonella specific antibodies are used as labels. A portable electronic platform was used to acquire the data (Freitas et al., 2012; Martins et al., 2009, 2010).

\section{Materials and methods}

\subsection{Media and buffers}

Luria Bertani (LB) agar plates were prepared by adding either $1.2 \%$ or $0.6 \%$ of agar to the liquid LB medium to get standard agar or soft agar medium, respectively. Phosphate buffer (PB; $100 \mathrm{mM}$ $\mathrm{NaH}_{2} \mathrm{PO}_{4}, 100 \mathrm{mM} \mathrm{Na}_{2} \mathrm{HPO}_{4}, \mathrm{pH}$ 7.4); PB Tw20 (PB with $0.02 \%$ (v/v) of Tween 20); SM buffer (100 mM NaCl, $8 \mathrm{mM} \mathrm{MgSO}_{4}, 50 \mathrm{mM}$ Tris- $\mathrm{HCl}, \mathrm{pH} 7.5)$; MOPS buffer (100 mM 3-(N-morpholino) propanesulfonic acid, $\mathrm{pH}$ 5.7); TE buffer (10 mM Tris- $\mathrm{HCl}, 1 \mathrm{mM}$ EDTA, pH 7.4); and Bovine serum albumin (BSA), $1 \%(\mathrm{w} / \mathrm{v})$ in water were used, where all reagents were acquired from Sigma.

\subsection{Bacteriophages and bacterial strains}

PVP-SE1 was isolated from a Regensburg (Germany) wastewater plant in the context of a European Project (Phagevet-P). Salmonella Enteritidis strain S1400 was used as host (Sillankorva et al., 2010). Campylobacter coli phage vB_CcoM-IBB_35, isolated from poultry intestines, was used as negative control (Carvalho et al., 2010a).

\subsection{Phage propagation and buffer exchange}

The phages were produced using the double layer agar technique as described by Sambrook and Russell (2001) and resuspended in SM buffer. Exchange of SM buffer by MOPS buffer was needed to avoid the presence of amine groups from SM buffer which may interfere with the surface chemistry adopted for phage immobilization on solid substrates. Buffer exchange was made using a Vivaspin 500 centrifugal concentrator (MW $100 \mathrm{kDa}$ ). Following the buffer exchange the concentration of phage was verified using the double layer agar technique.

\subsection{Induction of Salmonella into viable but non-culturable (VBNC) state}

Bacteria were induced to enter the VBNC state by using sodium hypochlorite (commercial bleach-stock concentration 5\%) at different concentrations. A single colony of Salmonella (S1400) was inoculated in $20 \mathrm{~mL}$ of $\mathrm{LB}$ broth and incubated overnight at $37^{\circ} \mathrm{C} / 200 \mathrm{rpm}$. 
Following the pre-inoculation, $1 \mathrm{~mL}$ was transferred to $15 \mathrm{~mL}$ of fresh LB broth and incubated for approximately $2-3 \mathrm{~h}$ at $37^{\circ} \mathrm{C} /$ $200 \mathrm{rpm}$ until the optical density at $600 \mathrm{~nm}\left(\mathrm{OD}_{600}\right)$ reached $0.5-$ 0.7 (concentration at $\sim 1.0 \times 10^{7} \mathrm{CFU} / \mathrm{mL}$ ). Cells were washed and resuspended in PB. From the stock solution, aliquots of $500 \mu \mathrm{L}$ of bacteria were transferred to $1.5 \mathrm{~mL}$ microtubes and centrifuged $\left(4{ }^{\circ} \mathrm{C}, 2370 \mathrm{~g}\right.$ for $15 \mathrm{~min}$ ), the supernatant was removed and $1 \mathrm{~mL}$ of each of the following concentrations of bleach was added to the bacterial pellet: $0.01000 \%, 0.00875 \%, 0.00750 \%, 0.00625 \%$, $0.00500 \%, 0.00250 \%$, and $0.00125 \%(\mathrm{v} / \mathrm{v})$. The serial dilutions of bleach were done with milli-Q water. Untreated cells were incubated with milli-Q water only. The samples were mixed at $200 \mathrm{rpm}$ for $1 \mathrm{~min}$ at room temperature. Following chlorination, the suspensions were centrifuged at $3420 \mathrm{xg}$ for $10 \mathrm{~min}$ at $4{ }^{\circ} \mathrm{C}$ and washed twice with cold PB. The number of culturable cells (after bleach treatment) was determined based on colony counting and expressed in colony forming units (CFU).

\subsection{Determination of cell viability}

Cell viability was assessed after submitting bacteria to different bleach concentrations using the LIVE/DEAD ${ }^{\circledR}$ BacLight ${ }^{\mathrm{TM}}$ Bacterial Viability and Counting Kit (Molecular Probes). SYTO9 and PI dyes were used, accordingly to manufacturer's instructions. Upon staining, cells were analyzed either by epifluorescence microscopy (OLYMPUS BX51 EXTREMO microscope) or by flow cytometry (BD LSRII flow cytometer using FACS DIVA software for acquisition; BD Biosciences). For absolute cell quantification, $6 \mu \mathrm{m}$ diameter microspheres were used at a known concentration in the flow cytometry acquisition. Flow cytometry data was analyzed using the Flowjo software (Tree Star, Ashland, OR).

\subsection{Phage lysis time and adsorption studies}

Salmonella cell suspensions were treated with bleach as previously described or heat-killed after $10 \mathrm{~min}$ at $70{ }^{\circ} \mathrm{C}$ in a thermoblock for $1.5 \mathrm{~mL}$ microtubes. $1 \mathrm{~mL}$ of each Salmonella sample was infected with PVP-SE1 phage at a multiplicity of infection (MOI) of 0.001 , which refers to the number of phages that were added per cell. Samples were taken immediately after infection (time 0 ) and after $20 \mathrm{~min}$ and $40 \mathrm{~min}$ of phage inoculation, followed by 10 -fold dilution in MOPS and centrifugation at $10,000 \mathrm{~g}$ for $10 \mathrm{~min}$. The supernatant was 10 -fold serially-diluted in MOPS and plated to assess the concentration of PFU (plaque forming unit).

The phage adsorption fraction was calculated by dividing the PFU concentration at each time point by the initial phage concentration.

To assess the phage lysis time viable exponential phase grown Salmonella cells were used. The procedure adopted was identical to the adsorption assays except that the samples were taken from cell cultures infected with phages from 0 to 80 min (every $10 \mathrm{~min}$ ), immediately plated (without being centrifuged) and their concentration determined by the double-layer agar plate method in LB medium.

\subsection{Phage immobilization on Au surfaces}

Cr $5 \mathrm{~nm} / \mathrm{Au} 40 \mathrm{~nm}$ thin film layers were sputtered (Kenosistec sputtering tool) over a silicon wafer. The wafer was then spincoated with a photoresist (PR) polymer (AZ1505 AZ Electronic Materials) for surface protection and diced in $7 \times 7 \mathrm{~mm}^{2}$ dies using an automatic dicing saw (Disco, DAD3350). The PR protective layer was removed prior to surface utilization by a dedicated solvent (microstrip 3001, Fujifilm, $65{ }^{\circ} \mathrm{C}$ for $2 \mathrm{~h}$ ). Substrates were then rinsed with isopropanol (IPA) and milli-Q water and dried under a nitrogen stream. To further remove any PR residues and other organic contaminants, the $\mathrm{Cr} / \mathrm{Au}$ substrates were exposed to ultraviolet light/ozone plasma (Novascan Technologies Inc., PSDP-UVT series, IA, USA) for $15 \mathrm{~min}$ at $50^{\circ} \mathrm{C}$. The gold surface was then functionalized with a heterobifunctional linker, the sulfo-LC-SPDP (sulfosuccinimidyl 6-[3'-(2-pyridyldithio)-propionamido] hexanoate). A droplet of $20 \mu \mathrm{L}$ of sulfo-LC-SPDP at $1 \mathrm{mg} / \mathrm{mL}$ in $\mathrm{PB}$ was placed over the gold substrate covering the entire surface ( $1 \mathrm{~h}$ at $\mathrm{RT}$ ). The substrates were then rinsed with PB and milli-Q water and blow-dried with a nitrogen gun. A phage solution in MOPS buffer $\left(\sim 1 \times 10^{10}\right.$ phages $\left./ \mathrm{mL}\right)$ or a polyclonal anti-Salmonella antibody (PA1-20811, Thermo Scientific) in PB solution $(200 \mu \mathrm{g} / \mathrm{mL})$ was then spotted in discrete areas of the substrate ( $\sim 0.5 \mu \mathrm{L}$ spots) and allowed to immobilize for $2 \mathrm{~h}$ at RT. The excess of phage was removed by rinsing with MOPS buffer and a solution of BSA at $1 \%(\mathrm{w} / \mathrm{v})$ in TE buffer (dispensed over the whole surface and allowed to react for $1 \mathrm{~h}$ to block the free gold areas). After rinsing the excess of BSA in PB, a Salmonella Enteritidis sample was dispensed over the functionalized surface and allowed to react for $40 \mathrm{~min}$. The unbound cells were washedout by substrate dipping and rinsing in PB. The functionalization protocol was performed at RT inside a humidified Petri dish to prevent evaporation of the spotted solutions.

Spot pictures were taken with an optical stereomicroscope (Nikon SMZ 1500) equipped with a CCD camera and analyzed using the image processing software ImageJ.

\subsection{MR-biochip measurement}

The MR-biochip was produced at INESC MN through a dedicated microfabrication process (Martins et al., 2009) and wirebonded to a PCB chip-carrier. Wires were protected with silicone gel. The probe sites on the MR biochip terminate with exposed $\mathrm{Cr} / \mathrm{Au}$ pads, underneath which lie the magnetoresistive sensors that will detect the magnetic nanoparticle labels. Briefly, the MR chip architecture comprises two distinct sensing areas arranged in two columns. Each column is composed of 3 groups of $5 \mathrm{U}$ shaped $2.5 \times 80 \mu \mathrm{m}^{2}$ spin-valve sensors. One of the sensors acts as reference (no phage probe attached).

The MR-biochip functionalization follows the same protocol previously described for $\mathrm{Cr} / \mathrm{Au}$ substrates. A $1 \mu \mathrm{L}$ droplet of Salmonella-specific phage was spotted over the left column of sensors (12 sensors) and a non-specific phage (Campylobacter phage) on the right column of sensors (12 sensors). After functionalization, the MR-chip was introduced on the portable reading platform (Germano et al., 2009) developed at INESC-ID, and the microfluidic system sealed. The sensors were biased by a $1 \mathrm{~mA}$ current while an external magnetic field ( $3 \mathrm{mT}$ DC bias field and $1.35 \mathrm{mT}_{\mathrm{rms}}$ AC field at $211 \mathrm{~Hz}$ ) was applied (these fields will be used later to magnetize the MNPs labels when present). The baseline signal was first acquired for $10 \mathrm{~min}$ with $\mathrm{PB}$ inside the microfluidic channel $(0.5 \mu \mathrm{L}$ total volume). Test solutions with Salmonella Enteritidis at $\sim 1.0 \times 10^{8}$ cells $/ \mathrm{mL}$ were introduced inside the channel with the aid of a syringe pump (New Era NE-300), and allowed to settle down for 40 min (phage-Salmonella recognition). The unbound bacteria were washed-out by rinsing with a solution of PB Tw20 at a flow rate of $5 \mu \mathrm{L} / \mathrm{min}$. The antibody-conjugated MNPs (prepared as described below) were then introduced inside the channel and allowed to settle for 30 min while signal acquisition was recorded for all sensors sequentially (Salmonella-antibody-MNP recognition). The unbound MNPs were washed-out with PB Tw20 at a flow rate of $50 \mu \mathrm{L} / \mathrm{min}$ for $5 \mathrm{~min}$. The difference between the signal acquired after washing and the baseline signal ( $\Delta V_{\text {binding }}$ ) is proportional to the number of cells bound to the sensor surface. For sensor to sensor and chip to chip comparison purposes the $\Delta V_{\text {binding }}$ signal was 
normalized to each sensor baseline signal $\left(V_{\text {sensor }}\right)$ at the measurement conditions, as explained by Martins et al. (2009).

\subsection{Antibody-conjugated MNPs preparation}

Commercial $250 \mathrm{~nm}$ Protein A modified MNPs (Nanomag, Micromod) were used. $1 \mu \mathrm{L}$ of MNPs stock solution $\left(4.9 \times 10^{11}\right.$ particles $/ \mathrm{mL}$ ) was transferred to a microtube, placed in a magnetic concentrator (Dynal-biotech) to remove the supernatant, and washed twice in $100 \mu \mathrm{L}$ of PB Tw20. Then, $1 \mu \mathrm{L}$ of anti-Salmonella polyclonal antibody (stock concentration at $1 \mathrm{mg} / \mathrm{mL}, \mathrm{PA} 1-20811$, Thermo Scientific) was added to the MNPs in a total volume of $5 \mu \mathrm{L}$ of PB Tw20 and allowed to react for $45 \mathrm{~min}$ at $200 \mathrm{rpm}$ and RT. An affinity reaction links the Protein A of the MNPs to the Fc region of the antibody. The unbound antibody was removed by the same magnetic separation procedure. The functionalized MNPs were finally resuspended in $5 \mu \mathrm{L}$ of PB Tw20 and injected over the chip.

\subsection{Statistical analysis}

All data are represented as mean $\pm \mathrm{SD}$ (standard deviation). For Figs. 2 and 3, means were compared using two-way ANOVA followed by the Bonferroni post hoc test. Differences were considered significant whenever $p<0.05$ and represented as * for $p<0.05$, ** for $p<0.001$ and $* * *$ for $p<0.0001$.

\section{Results and discussion}

\subsection{Induction of VBNC physiological state in Salmonella}

Since the goal of this work was to prove the phage ability to detect the VBNC state of bacterial cells, a process was first developed capable of affecting cell viability in a controlled manner that would not lead to killing or lysing the entire cell population. For this purpose different bactericidal and bacteriostatic compounds, known to induce the VBNC state in Salmonella cells, were tested (data not shown). From those, sodium hypochlorite (commercial bleach) was found to be the most efficient in producing VBNC cells.

Eight different concentrations of bleach, ranging from $0 \%$ to $0.01 \%(\mathrm{v} / \mathrm{v})$, were tested. As shown in Fig. 1A (linear curve), the break-point, defined as the concentration at which $100 \%$ of the cells lose their ability to form colonies in solid, non-selective medium, was found to be $0.006 \%$. For bleach concentrations below the break-point, at least a fraction of the population is still viable and able to grow in solid medium, while above this concentration no colonies are observed. However, when exposed to fresh liquid medium under adequate growth conditions all tested concentrations of bleach, even above the break-point, showed cell growth (Supplementary data, Fig. S2.1). This observation, complemented with results from other analytical methods, such as fluorescence microscopy and flow cytometry (Fig. 1B and C), indicates that bleach concentrations above $0.006 \%$ can induce Salmonella Enteritidis cells to enter a VBNC state.

In flow cytometry assays, as previously explained, using the LIVE/DEAD BacLight kit, live bacteria with intact membranes are supposed to appear green and dead bacteria with damaged membranes to emit red. However, in bleach-treated cells, intermediate colors, from yellow to orange, were also observed under an epifluorescence microscope (Fig. 1B) indicating the existence of other cell states where membranes present different degrees of damage (compromised cells).

In order to quantitatively determine the relative and absolute proportion of the different cell populations (classified as live, dead or compromised), flow cytometry analyses were conducted for the different cell samples (Fig. $1 \mathrm{~A}$ bars and $1 \mathrm{C}$ ). Untreated bacteria appeared mostly as live cells (SYTO9+, PI-), while treated samples, with increasing bleach concentrations, were either compromised or dead (Fig. 1A bars and 1C).

Additionally, to correlate flow cytometry data with the cell's metabolic activity in each physiological state the PrestoBlue ${ }^{\mathrm{TM}}$ assay from Life Technologies was used. The compound resazurin is effectively reduced (from blue to pink) only by enzymatic activity in viable cells. Populations treated with up to $0.01 \%$ of bleach, despite not being culturable, were still able to reduce the resazurin reagent, while heat-killed cells presented no activity (Supplementary data, Fig. S2.1).

The VBNC state has been associated to a survival mechanism of the bacteria upon exposure to harsh but sub-lethal conditions (Mizunoe et al., 1999). This represents a major problem to water treatment factory plants and other industrial facilities that typically use $0.5-1 \%(\mathrm{v} / \mathrm{v})$ bleach as a disinfectant in combination with traditional cell cultures as an inspection method. These results prompted us to study whether the Salmonella-specific phage PVPSE1 would be able to detect bacteria at the VBNC state.

\subsection{Profile of phage adsorption to cells in different physiological states}

The PVP-SE1 is a virulent phage able to lyse bacterial cells. In a solid state biosensing system this could be a limitation on the recognition of live organisms. Such characteristic has refrained researchers from including these phages in their detection systems (Santos et al., 2010). In this work, the phage inoculation conditions (i.e. buffer $\mathrm{pH}$ and ionic strength) were studied in order to avoid Salmonella cells from lysing within the assay time frame. Fig. 2A shows percentual phage adsorption to Salmonella Enteritidis vs time in solution to assess both the lysis time or latent period and adsorption rate. For the lysis time studies, the bacterial cells were lysed and the total number of phages was quantified by the double layer agar technique (Sambrook and Russell, 2001). The plaque forming units (PFU) are directly related to the number of phages in the sample (Fig. 2B and C). It was observed that no cell lysis occurred up to $80 \mathrm{~min}$ after phage inoculation. This unusual large period for cell infection and burst may be related to the fact that the phage is not present in ideal infection conditions. For biosensing purposes this observation opens novel opportunities to explore the potential of lytic phages while circumventing their greatest limitation (Carvalho et al., 2010b).

After optimization of non-lysing conditions, the phage ability to recognize different cell physiological states (viable, VBNC and dead) was evaluated. For this purpose VBNC cells were prepared by treatment with bleach at $0.01 \%$ and dead cells prepared by heating at $70{ }^{\circ} \mathrm{C}$ for $10 \mathrm{~min}$ (where no bacteria could be recovered after resuscitation assays). Results confirmed that, despite being present in sub-optimal host infection conditions, the phage adsorption capability was conserved, maintaining its potential to be used as a detection tool. It was found that the phage could efficiently adsorb to both viable and VBNC Salmonella cell suspensions. Furthermore, viable cells and VBNC cells were both promptly recognized by the phage ( $<20 \mathrm{~min}$ ) while dead cells presented a lower adsorption rate. Although there is a slight increase in the adsorption (19\%) to dead cells with time of inoculation (from 20 to $40 \mathrm{~min}$ ), the adsorption to viable cells (78\%) is more efficient. This indicates that phages may have biological mechanisms which link them preferably to viable cells. This observation is expected to have a major impact in the existing bioanalytical field once phages can be used as a bioelement to significantly reduce the number of false-positive and falsenegative results presented by traditional molecular detection systems. 
A

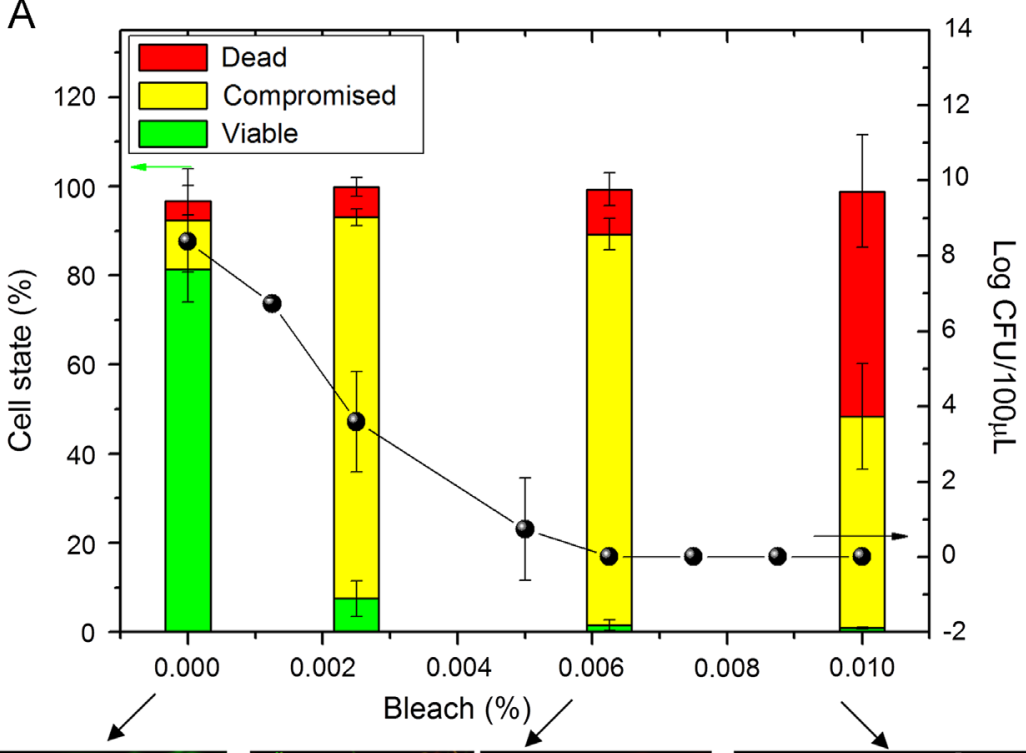

B
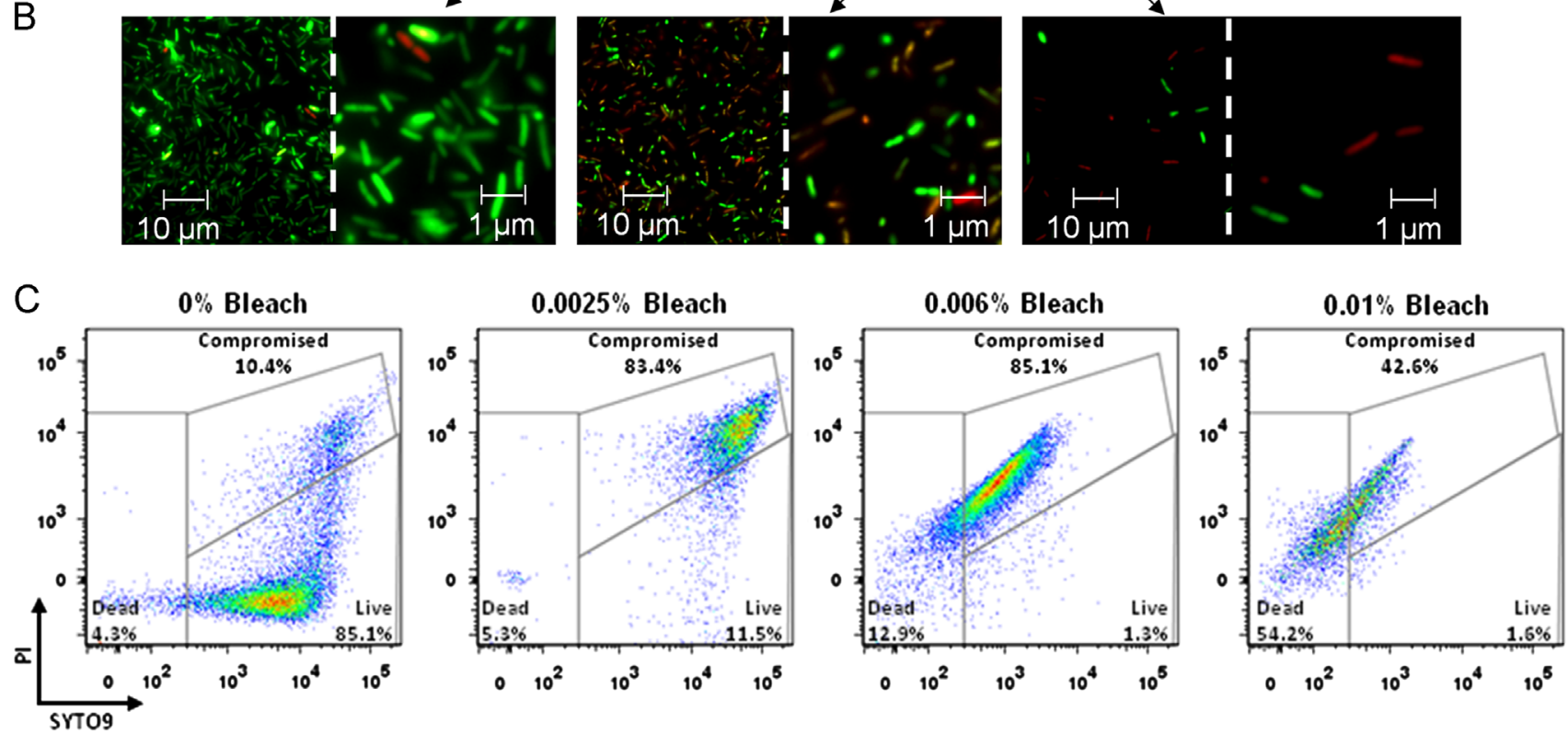

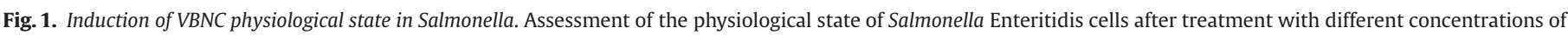

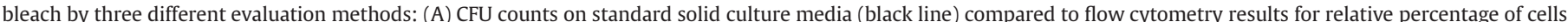

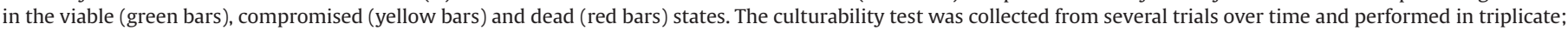

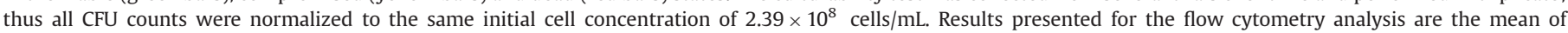

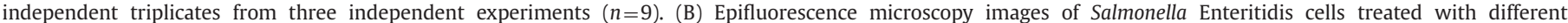

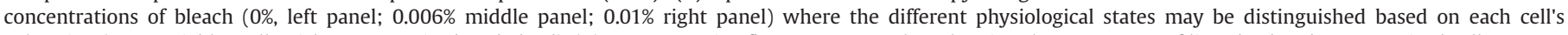

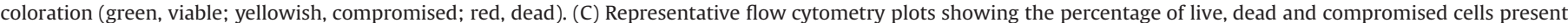

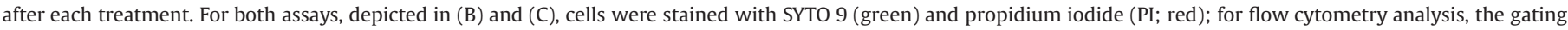

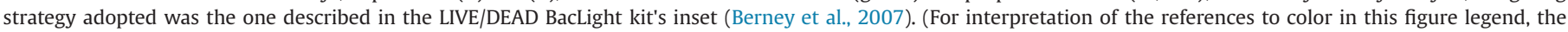
reader is referred to the web version of this article.)

\subsection{Phage performance as a biorecognition element}

The phage's validation as a biorecognition tool will be centered on its immobilization on a solid sensing surface. After optimization of the surface chemistry (Supplementary data, Fig. S3.1 and S3.2), the phage was immobilized on an Aurface at discrete areas by manual spotting. Viable, VBNC and dead cell suspensions were incubated for $40 \mathrm{~min}$ with the immobilized phage. The degree of phage's recognition was evaluated through a semi-quantitative optical method to measure the cell's surface density over the phage spot area. Fig. 3A shows relative surface density of captured cell for varying populations of viable + VBNC cells (with increasing number of dead cells). Though cell density results cannot be directly compared in absolute terms with other quantitative data (e.g. cytometry and MR-sensor) the observed results follow the same trend as that shown in Fig. 1A (bars plot). Also according to phage adsorption rates in solution, the immobilized phages were able to discriminate between viable and dead cells. This resulted in reduced cell densities for samples with increasing number of dead cells (Fig. 3A) but proportional to the relative concentration of viable plus VBNC cells (compromised population) obtained by flow cytometry analysis (Fig. 1A-bars plot).

Also important to notice is that even after $40 \mathrm{~min}$ of incubation, dead cells were completely undetected by the phage as opposed to adsorption results for cells in solution (Fig. 2-triangles). A possible explanation could be that phages bound weakly to dead cells are easily released along the several washing steps performed in solid surface experiments. 

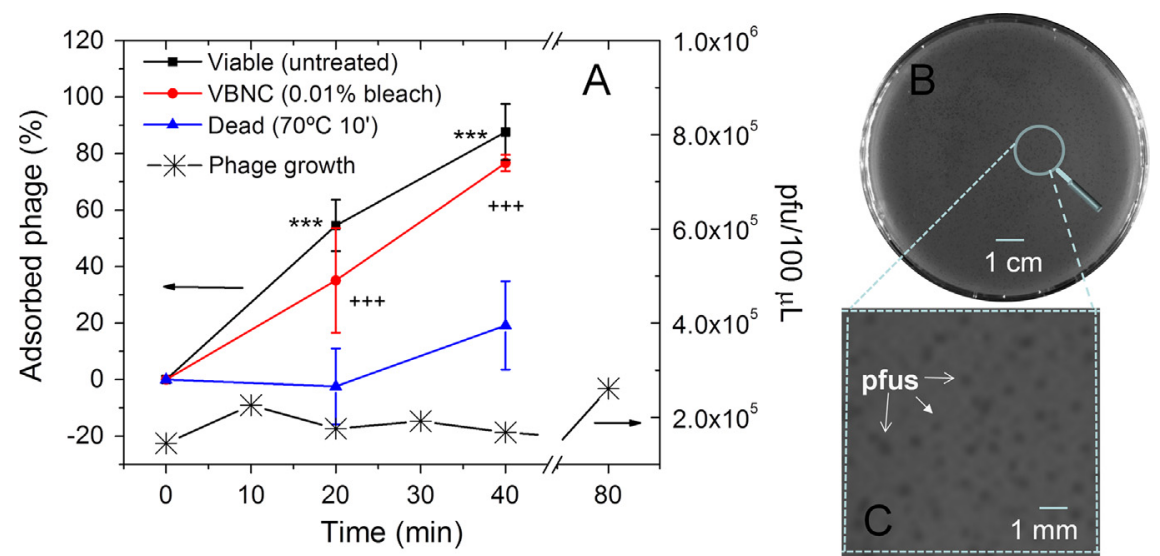

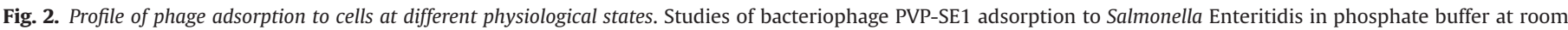

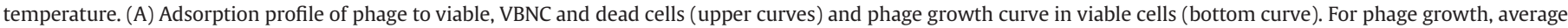

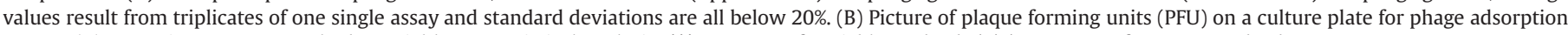
counts. (C) Zoom-in over PFU on the bacterial lawn. Statistical analysis: ${ }^{* * *} p<0.0001$ for viable vs dead, ${ }^{+++} p<0.0001$ for VBNC vs dead; two-way ANOVA.

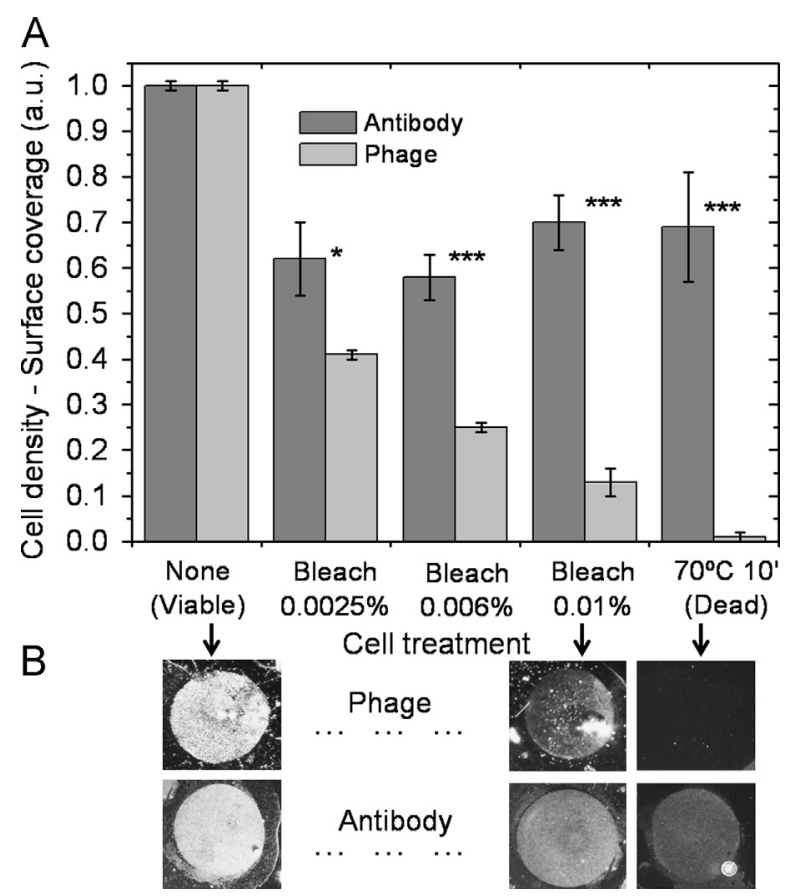

Fig. 3. Phage vs antibody performance as a biorecognition element. Density of cells specifically captured by phage and antibody spots, covalently immobilized on gold solid surface. (A) The surface coverage was analyzed by Image J software. (B) Stereoscope pictures for representative spots of Salmonella cells specifically recognized by phage PVP-SE1 (top) and anti-Salmonella antibody (bottom). Statistical analysis for phage vs antibody results: ${ }^{*} p<0.05,{ }^{* * *} p<0.0001$, two-way ANOVA.

The phage detection efficiency for the several cell physiological states was directly compared with an anti-Salmonella polyclonal antibody immobilized on the same Au surface (Fig. 3B-bottom pictures). The antibody indiscriminately recognizes and captures all cells, independently of their physiological state, reaching almost constant cell densities for samples with different proportions of viable to dead cells and even for heat-killed cells, thus resulting in false positive results.

These results indicate that the phage and the antibody are not recognizing the same cell membrane epitopes and may work successfully in combination. In fact, one major concern when developing biomolecular recognition strategies, in particular "sandwich" type assays where two biorecognition elements may specifically bind to the same target analyte, is the competition for the target receptors (epitopes). Identical biorecognition elements may hinder each other's proper attachment. This is a common scenario in standard immunoassays where a labeling antibody may block the epitopes to the capture antibody or vice versa.

\subsection{Phage-based magnetoresistive biochip for cell viability assessment}

The feasibility of developing a "sandwich" phage-based biosensing system and its potential as a cell viability determination tool was assessed making use of an existent magnetoresistive (MR) biochip (Freitas et al., 2012; Martins et al., 2009, 2010) and respective electronic reader (Germano et al., 2009). The phage immobilization procedure previously optimized for gold surfaces (Supplementary data, Fig. S3.1 and S3.2) was transferred to the MR biochip. The functionalized biochip was then used for quantitative analysis of Salmonella samples in different physiological states.

The biomolecular recognition strategy used on the biochip combines the phage and a magnetically-labeled antibody as recognition and labeling elements, respectively. After the functionalization of the biochip with PVP-SE1 bacteriophage, each cell solution was loaded over the chip surface and incubated. Then, the magnetically labeled antibodies were loaded over the cells and let to specifically react. After washing, the magnetic fringe field created by the labels was detected as a variation on the sensor resistance. Fig. 4A (dashed line and black dots) shows the biosensor normalized output for decreasing concentrations of viable+ VBNC cells.

Replica samples to those loaded on the biochip were analyzed by flow cytometry using the LIVE/DEAD ${ }^{\circledR}$ BacLight $^{\mathrm{TM}}$ Bacterial Viability and Counting kit.

The bars in Fig. 4A correspond to the absolute concentrations of viable, compromised and dead cells as obtained from this kit.

Cytometry results corroborate those obtained by MR detection where the absolute number of viable cells corresponds in amplitude to the sensor signal. The high sensitivity of the magnetoresistive biosensor allows determination down to 3-4 cells per sensor. The integration of the magnetoresistive sensor with the phage probes allows a clear detection of VBNC, as compared with the "unknown" or "compromised" tags associated with flow cytometry analysis. The biochip also requires a much lower sample volume (less than a microliter) when compared to flow cytometry (hundreds of microliters) and profits from a hand-held system as sample reader (Germano et al., 2009). 
A

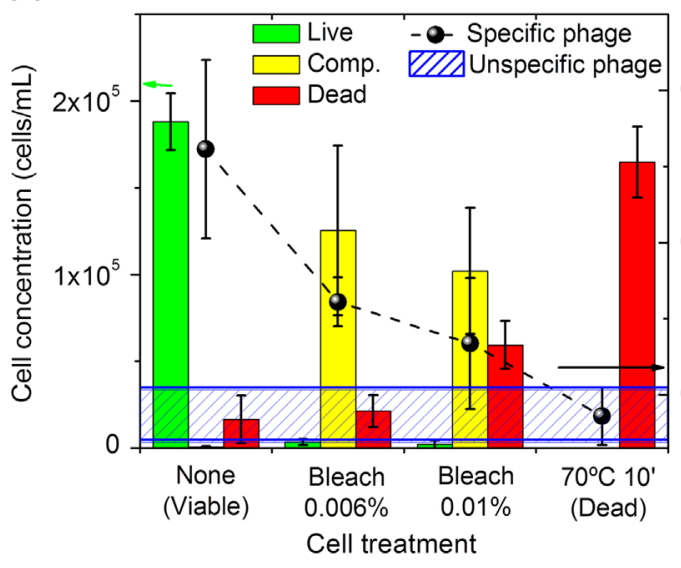

B 0.02

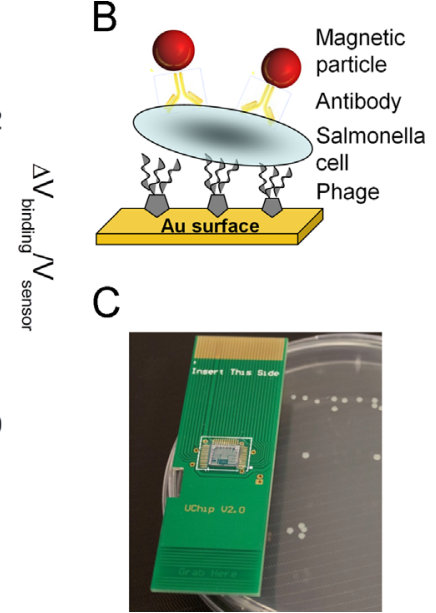

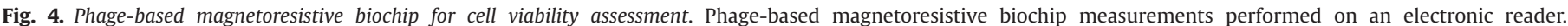

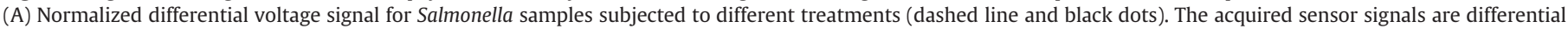

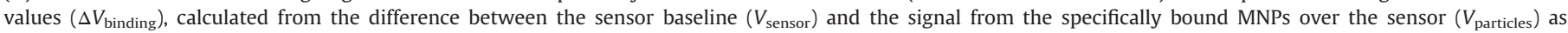

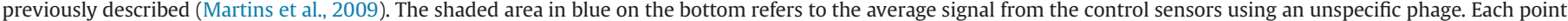

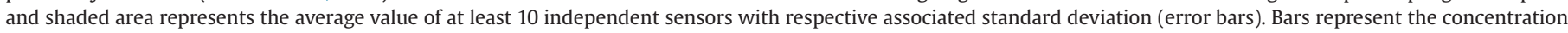

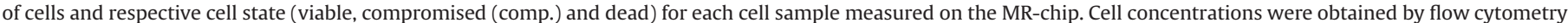

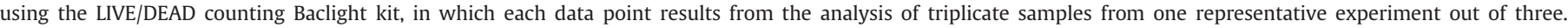

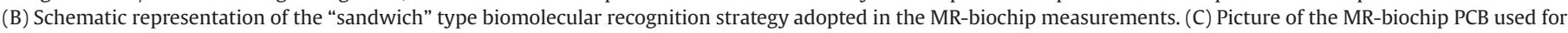
the detection of Salmonella cells, shown on a standard cell culture plate.

\section{Conclusions}

The lytic phage PVP-SE1 was explored as an alternative biorecognition element for bacterial detection and viability assessment. Taking into account the problematic occurrence of false positives associated with DNA-chips and the high production costs, poor stability and cross-reactivity related to immuno-chips, the development of phage-based biochips emerges as a valuable tool. The feasibility to immobilize phages on sensing surfaces and conjugate this biomolecular tool with electronic analytical devices without losing functionality was proven. A magnetoresistive biochip was used as a proof-of-concept system to demonstrate the potential of the phage as a biorecognition element. The combined use of the magnetoresistive sensor with the phage probes allowed a clear detection of viable from dead Salmonella cells.

\section{Acknowledgments}

The authors want to thank Tomás Dias and José Bernardo for their help in chip processing and encapsulation. INESC-ID and in particular José Germano are acknowledged for provision and support on the biochip electronic reader.

\section{Appendix A. Supplementary material}

Supplementary data associated with this article can be found in the online version at http://dx.doi.org/10.1016/j.bios.2013.08.053.

\section{References}

Awais, R., Fukudomi, H., Miyanaga, K., Unno, H., Tanji, Y., 2006. Biotechnology Progress 22 (3), 853-859.

Banihashemi, A., Van Dyke, M.I., Huck, P.M., 2012. Journal of Applied Microbiology 113 (4), 863-873.

Baudart, J., Coallier, J., Laurent, P., Prévost, M., 2002. Applied and Environmental Microbiology 68 (10), 5057-5063.

Berney, M., Hammes, F., Bosshard, F., Weilenmann, H., Egli, T., 2007. Applied and Environmental Microbiology 73 (10), 3283-3290.

Besnard, V., Federighi, M., Cappelier, J.M., 2000. Letters in Applied Microbiology 31 (1), 77-81.
Boehm, D.A. Gottlieb, P.A., Hua, S.Z., 2007. Sensors and Actuators B-Chemical 126 (2), 508-514.

Breeuwer, P., Abee, T., 2000. International Journal of Food Microbiology 55 (1-3), 193-200.

Caron, G.N.-V., Stephens, 1998. Journal of Applied Microbiology 84 (6), 988-998.

Carvalho, C., Susano, M., Fernandes, E., Santos, S., Gannon, B., Nicolau, A., Gibbs, P., Teixeira, P., Azeredo, J., 2010a. Letters in Applied Microbiology 50 (2), 192-197.

Carvalho, C.M., Gannon, B.W., Halfhide, D.E., Santos, S.B., Hayes, C.M., Roe, J.M., Azeredo, J., 2010b. BMC Microbiology 10, 232-242.

Deere, D., Porter, J., Edwards, C., Pickup, R., 1995. FEMS Microbiology Letters 130 (2-3), 165-169.

Duncan, S., Glover, L.A., Killham, K., Prosser, J.I., 1994. Applied and Environmental Microbiology 60 (4), 1308-1316.

Edgar, R., McKinstry, M., Hwang, J., Oppenheim, A.B., Fekete, R.A., Giulian, G., Merril, C., Nagashima, K., Adhya, S., 2006. Proceedings of the National Academy of Sciences of the United States of America 103 (13), 4841-4845.

Firmesse, O., Morelli, E., Vann, S., Carpentier, B., 2012. International Journal of Food Microbiology 159 (3), 179-185.

Freitas, P.P., Cardoso, F.A., Martins, V.C., Martins, S.A.M., Loureiro, J., Amaral, J., Chaves, R.C., Cardoso, S., Fonseca, L.P., Sebastiao, A.M., Pannetier-Lecoeur, M., Fermon, C., 2012. Lab on a Chip 12 (3), 546-557.

Germano, J., Martins, V.C., Cardoso, F.A., Almeida, T.M., Sousa, L., Freitas, P.P., Piedade, M.S., 2009. Sensors 9 (6), 4119-4137.

Hagens, S., Loessner, M.J., 2007. Applied Microbiology and Biotechnology 76 (3), 513-519.

Ivnitski, D., Abdel-Hamid, I., Atanasov, P., Wilkins, E., 1999. Biosensors \& Bioelectronics 14 (7), 599-624.

Joux, F., Lebaron, P., 2000. Microbes and Infection 2 (12), 1523-1535.

Keer, J.T., Birch, L., 2003. Journal of Microbiological Methods 53 (2), 175-183.

Khamisse, E., Firmesse, O., Christieans, S., Chassaing, D., Carpentier, B., 2012. International Journal of Food Microbiology 158 (2), 163-168.

Lu, Y., Yang, W., Shi, L., Li, L., Alam, M.J., Guo, S., Miyoshi, S.-i., 2009. Journal of Health Science 55 (5), 820-824.

Martins, V.C., Cardoso, F.A., Germano, J., Cardoso, S., Sousa, L., Piedade, M., Freitas, P.P. Fonseca, L.P., 2009. Biosensors \& Bioelectronics 24 (8), 2690-2695.

Martins, V.C., Germano, J., Cardoso, F.A., Loureiro, J., Cardoso, S., Sousa, L., Piedade, M., Fonseca, L.P., Freitas, P.P., 2010. Journal of Magnetism and Magnetic Materials 322 (9-12), 1655-1663.

Mizunoe, Y., Wai, S.N., Takade, A., Yoshida, S., 1999. Archives of Microbiology 172 (1), 63-67.

Nebe-von-Caron, G., Stephens, P.J., Hewitt, C.J., Powell, J.R., Badley, R.A., 2000. Journal of Microbiological Methods 42 (1), 97-114.

Nugen, S.R., Baeumner, A.J., 2008. Analytical and Bioanalytical Chemistry 391 (2), 451-454.

Nybroe, O., 1995. FEMS Microbiology Ecology 17 (2), 77-83.

Oda, M., Morita, M., Unno, H., Tanji, Y., 2004. Applied and Environmental Microbiology 70 (1), 527-534.

Oliver, J.D., 2005. Journal of Microbiology 43, 93-100.

Oliver, J.D., 2010. FEMS Microbiology Reviews 34 (4), 415-425.

Phe, M.-H., Dossot, M., Guilloteau, H., Block, J.-C., 2005. Water Research 39 (15), 3618-3628. 
Sambrook, J., Russell, D.W., 2001. Molecular Cloning: A Laboratory Manual. Cold Spring Harbor Laboratory Press, Cold Spring Harbour, New York.

Santos, S.B., Fernandes, E., Carvalho, C.M., Sillankorva, S., Krylov, V.N., Pleteneva, E.A., Shaburova, O.V., Nicolau, A., Ferreira, E.C., Azeredo, J., 2010. Applied and Environmental Microbiology 76 (21), 7338-7342.

Schofield, D.A., Sharp, N.J., Westwater, C., 2012. Bacteriophage 2 (2), 105-283.

Sillankorva, S., Pleteneva, E., Shaburova, O., Santos, S., Carvalho, C., Azeredo, J., Krylov, V., 2010. Journal of Applied Microbiology 108 (4), 1175-1186.

Singh, A., Arutyunov, D., Szymanski, C.M., Evoy, S., 2012. Analyst 137 (15), 3405-3421.

Smartt, A.E., Xu, T.T., Jegier, P., Carswell, J.J., Blount, S.A., Sayler, G.S., Ripp, S., 2012. Analytical and Bioanalytical Chemistry 402 (10), 3127-3146.
Suller, M.T.E., Lloyd, D., 1999. Cytometry 35 (3), 235-241.

Tlili, C., Sokullu, E., Safaviah, M., Tolba, M., Zourob, M.M., 2013. Analytical Chemistry 85 (10), 4893-4901.

Velusamy, V., Arshak, K., Korostynska, O., Oliwa, K., Adley, C., 2010. Biotechnology Advances 28 (2), 232-254.

Weaver, J.L., 1998. Estimation of cell viability by flow cytometry, in: Jaroszeski, M.J., Heller, R. (Eds.), Flow Cytometry Protocols. Humana Press Inc., New Jersey, pp. $77-84$.

WHO, 2005. The fifty-eighth world health assembly. In: WHO (Ed.), International Health Regulations.WHO, Geneva.

Winding, A., Binnerup, S.J., Sørensen, J., 1994. Applied and Environmental Microbiology 60 (8), 2869-2875. 